\title{
Experimental study on the tribo-chemical smoothening process between self-mated silicon carbide in a water-lubricated surface- contact reciprocating test
}

\author{
Le JIN ${ }^{1}$, Herbert SCHEERER ${ }^{1, *}$, Georg ANDERSOHN ${ }^{1}$, Matthias OECHSNER ${ }^{1}$, Dieter HELLMANN ${ }^{2}$ \\ ${ }^{1}$ Center for Structural Materials, Technische Universität Darmstadt, Darmstadt 64283, Germany \\ ${ }^{2}$ KSB, Frankenthal (Pfalz) 67227, Germany \\ Received: 05 December 2017 / Revised: 05 February 2018 / Accepted: 23 April 2018 \\ C The author(s) 2018. This article is published with open access at Springerlink.com
}

\begin{abstract}
Silicon carbide $(\mathrm{SiC})$ can be tribo-chemically smoothened during a self-mated sliding procedure in the aqueous environment. As well reported in the point-contact tests, this smoothening process works well due to the abundant water as oxidant. After this smoothening process, the tribo-surface is well polished, a closely mated tribo-gap naturally forms, and an ultra-low friction state is built. However, water in the tribo-gap could be insufficient in industrial applications, e.g., the seal gap in mechanical seals. In this study, the tribo-chemical smoothening behavior in such environment was researched. A surface-contact reciprocating test was used to simulate the aqueous environment where water was insufficient. After tests, compared to the published results from the point-contact tests, the same ultra-low friction state was achieved. A part of the tribo-surface was tribo-chemically smoothened. The obtained smoothened surface microstructure was consistent with the published information. Meanwhile, severe abrasive wear occurred. A porous oxygen-rich layer was found existing beneath the abrasion-induced grooves, in which numerous smashed wear debris adhered on the worn surfaces. We concluded that the shortage of water initiated the severe abrasion, meanwhile the generated wear debris aggravated the wear condition. This understanding is instructive for developing new methods to avoid the severe abrasion in the same water insufficient environment.
\end{abstract}

Keywords: silicon carbide; surface-contact sliding friction; tribo-chemical smoothening; abrasion; ultra-low friction; mechanical seal

\section{Introduction}

Silicon carbide $(\mathrm{SiC})$ is widely used in tribological applications. Owing its high hardness, good abrasion resistance and excellent chemical stability, $\mathrm{SiC}$ holds more than $70 \%$ of the hard materials in mechanical seal faces [1]. However, its brittleness and high hardness bring difficulties on the machining process. During the manufacture of the mechanical seal face, two $\mathrm{SiC}$ surfaces are firstly well polished to get a low surface roughness value, and then the polished surfaces are assembled precisely to get a narrow seal gap (approx. $1 \mu \mathrm{m}$ or less width).

Besides the mechanical polishing, SiC surface can be tribo-chemically smoothened (or polished) [2-5]. It is a simple running-in process between the self-mated $\mathrm{SiC}$ surfaces in a water lubricated sliding procedure. After this process, the surfaces were smoothened. The surface roughness value Ra varied from $5 \mathrm{~nm}$ [3] to $25 \mathrm{~nm}$ [4]. Between these smoothened surfaces, the tribo-gap had an estimated width of $25 \mathrm{~nm}$ [4] to $80 \mathrm{~nm}$ [6]. Meanwhile, the tribo-pair achieved an ultra-low friction (ULF) state (friction coefficient is approx. 0.01) [2-5]. So far, the exact lubrication

* Corresponding author: Herbert SCHEERER, E-mail: scheerer@mpa-ifw.tu-darmstadt.de 
mechanism for ULF is still not in agreement. Some authors concluded that a fully hydrodynamic lubrication is responsible for the ULF state $[4,7,8]$, while the others tended to believe it is a mixed lubrication including a part of solid-solid boundary lubrication [6, 9-11].

A running-in process is needed to build the ULF state. This running-in procedure has been well researched on the basis of point-contact tests $[2-4,6$, 10]. During the point-contact tests, the contact region between the tribo-surfaces increases from a single point to a limited contact area, thus the mean contact pressure decreases. As soon as the mean contact pressure decreases to a critical value, the ULF state is built, the both surfaces are tribo-chemically polished, and the extremely narrow tribo-gap is formed. Despite the disagreement on the exact lubrication mechanism, all the publications admit this running-in process in a point-contact case.

However, in mechanical seals, the tribological condition is a surface-contact sliding friction. In this case, the lubricant cannot be abundant everywhere in the tribo-gap because of the sealing request. On this issue, in most of the published surface-contact tests, grooves or pits were textured on the tribo-surfaces to optimize the lubrication condition $[12,13]$. Guo et al. designed several pauses within a surface-contact test using other materials. During these pauses, water can be refilled onto the tribo-surface [14]. This is also different with the seal's condition. Presser et al. used a scaled seal test between the self-mated $\mathrm{SiC}$ flat surfaces without any texturing, obtaining deteriorated partial surfaces and a non-ULF state [15]. Therefore, it is still not clear if the tribo-chemical smoothening process can still function in the tribological condition similar with mechanical seals.

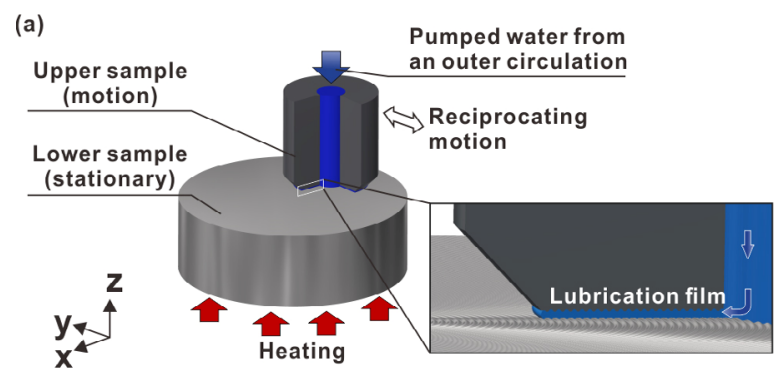

Fig. 1 Schematic diagram for the modified surface-contact oscillation frictional test method. (a) Schematic diagram for the tribo-samples, the tribo-gap, and the pumping lubricant; (b) basic dimensions of testing samples and wear scars.

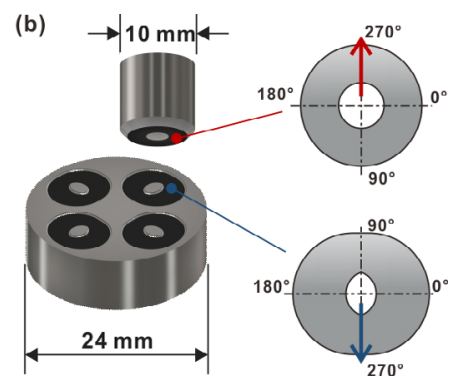

The motivation of this study is to seek if the tribochemical smoothening process could work in a tribocase similar with mechanical seals. It is meaningful to discuss this possibility. This is because if it works, it is not necessary any more to polish the surfaces and then assemble them to get a seal gap. Instead, two unpolished surfaces could be assembled directly in the mechanical seals and simply let them run-in in the aqueous environment. After running-in, a pair of closely mated tribo-chemically polished surfaces could be naturally generated.

In this study, a series of water lubricated surfacecontact sliding friction tests were conducted. Before testing, the tribo-surfaces were flat without any textured grooves or pits. Referenced from the actual seals, a hydrostatic pressure gradient was built from one side of the tribo-gap to the other. Thus, the lubricant was pumped flowing through the tribo-gap.

\section{Materials and methods}

\subsection{Surface-contact reciprocating frictional test}

A modified surface-contact reciprocating frictional test was used, as demonstrated in Fig. 1 [16, 17]. The sliding friction was conducted in the test chamber of SRV III (Optimol Instruments Prüftechnik $\mathrm{GmbH}$ ). The tribo-surfaces came from two vertical arranged cylinder samples. The lower sample was static while the upper sample performed a reciprocating motion. The upper sample had a coaxial bore hole in the center. An outer circulation was built to pump the lubricant from a tank through this bore hole into the heated tribo-gap. In this circulation, a gear pump was used to provide a stable, non-pulsed lubricant flow. The hydrostatic pumping pressure can be controlled 
maximum to 4 bar (from gauge). The temperature in the tribo-gap was measured by a sensor below the lower sample and controlled by SRV III.

The friction coefficient was measured by SRV III following DIN 51834-1:2010. During testing, SRV III measured the friction coefficient values at a frequency of $62.5 \mathrm{~Hz}$. The software calculated a peak-to-peak value from all detected friction coefficient values within $1 \mathrm{~s}$ [18]. According to the official information from Optimol Instruments Prueftechnik $\mathrm{GmbH}$, the provider of SRV III, "this peak-to-peak value represents frequently a static friction proportion in the tribo-gap at the turning points of the reciprocating movement". Then these peak-to-peak values were recorded every second, as the in-situ records. The mean value $(\bar{f})$ of the recorded friction coefficients during the last 5 min of each test was calculated to evaluate the final friction behavior.

In this study, each friction test was conducted for $240 \mathrm{~min}$ at constant parameters. The normal load was kept at $200 \mathrm{~N}$, thus the mean contact pressure was $4.8 \mathrm{MPa}$. The reciprocating frequency was $50 \mathrm{~Hz}$ with a $1 \mathrm{~mm}$ stroke, i.e., the total sliding distance was $1,440 \mathrm{~m}$. The hydrostatic pressure of the pumped lubricant was 2 bar (from gauge). The temperature varied from 40 to $120^{\circ} \mathrm{C}$ among different tests. During all tests, no liquid leakage was observed from the tribo-gap.

In this study, all frictional tests under the same tribological parameters and surface conditions were repeated 2 or 3 times.

\subsection{Material and testing specimen}

The testing cylindrical samples were made up of commercial sintered silicon carbide, manufactured by 3M Technical Ceramic (Grade F from the provider's catalog). The purity was higher than 99\%. Main properties of this $\mathrm{SiC}$ are listed in Table 1.

\subsection{Surface roughness}

The linear surface roughness was evaluated following DIN EN ISO 4287. The measurement equipment is Hommel-Etamic T8000 (Jenoptik AG), a stylus type profilometer. The in-depth resolution is less than $10 \mathrm{~nm}$. The distance between the adjacent detection points is $500 \mathrm{~nm}$. Within each partial surface, three
Table 1 Main properties of the $\mathrm{SiC}$ specimen.

\begin{tabular}{ll}
\hline Density $\left(\mathrm{g} / \mathrm{cm}^{3}\right)$ & 3.15 \\
Main grain size $(\mu \mathrm{m})$ & $<5$ \\
Vickers hardness HV1 $(\mathrm{GPa})$ & 24.5 \\
Compressive strength $(\mathrm{MPa})$ & $>2500$ \\
Thermal conductivity $(\mathrm{W} /(\mathrm{m} \cdot \mathrm{K}))$ & 130 \\
Porosity $(\%)$ & $<2.0$ \\
Phase composition & $\alpha-\mathrm{SiC}$ \\
Young's modulus $(\mathrm{GPa})$ & 430 \\
Fracture toughness $\mathrm{KIC}\left(\mathrm{MPa} \cdot \mathrm{m}^{0.5}\right)$ & 210 \\
Coefficient of thermal expansion, $\alpha\left(10^{-6} / \mathrm{K}\right)$ & $3.8-5.1$ \\
\hline
\end{tabular}

parallel scanning routes were detected, obtaining the surface roughness values (the arithmetical mean deviation of the assessed profile ( $\mathrm{Ra}$ ) and the average distance between the highest peak and lowest valley in each sampling length (Rz)). The mean value and standard deviation of these obtained $\mathrm{Ra}$ and $\mathrm{Rz}$ values were calculated.

In this study, the original sintered surfaces and the mechanical polished surfaces were tested, whose roughness values are listed in Table 2. The original sintered surfaces were reserved after the sintering process without any other manufacturing. The mechanical polished surfaces were further polished from the original sintered surfaces.

\subsection{Surface topographic analysis}

After the frictional tests, linear topography of the worn surface was analyzed using Hommel-Etamic T8000. To determine the actual mating condition at the final friction stage, two linear topographic measurements were carried out from both the upper and lower scars along the same routes (e.g., the $90^{\circ}$ and $270^{\circ}$ axis in Fig. 1(b)). The detected topographic curves were then combined to seek the mating condition between the two worn surfaces.

The three-dimensional (3D) surface morphology was examined using a Leica 3D microscope. In this evaluation, the in-depth resolution is $2 \mathrm{~nm}$ and the lateral resolution is $140 \mathrm{~nm}$.

Table 2 Surface roughness of $\mathrm{SiC}$ specimen.

\begin{tabular}{lcc}
\hline Origins & $\mathrm{Ra}(\mu \mathrm{m})$ & $\mathrm{Rz}(\mu \mathrm{m})$ \\
\hline $\begin{array}{l}\text { Original sintered surface } \\
\text { Mechanical polished surface } \\
\text { (polished from the original }\end{array}$ & $0.385 \pm 0.024$ & $3.294 \pm 0.741$ \\
\begin{tabular}{l} 
sintered surface) \\
\hline
\end{tabular} & & $0.501 \pm 0.103$ \\
\hline
\end{tabular}


Before tribo-tests, the topography of the original sintered surface and mechanical polished surface were evaluated (Fig. 2).

\subsection{Further analytical evaluations of the surface}

A scanning electron microscope (SEM) was used to capture the microstructure of worn surfaces. An energy dispersive X-ray analysis (EDX) was used to identify the elemental composition in specific positions. The beam voltage was $15 \mathrm{kV}$. The spot diameter of the electron beam was less than $10 \mathrm{~nm}$. But due to electron diffraction, the lateral resolution for EDX can become several hundred nanometers.

Focused ion beam (FIB) is an effective method to characterize materials in dimensions of emphasis on nanometer [19]. In this research, an FIB was used to cut the samples to analyze the cross-section beneath the worn surfaces. The cross-section was imaged by SEM, and EDX was conducted along the depth direction.

\section{Results and discussions}

\subsection{Friction coefficient}

Two typical in-situ friction coefficient records are listed in Fig. 3. Some of the tribo-tests achieved the ultra-low friction (ULF) state (Fig. 3(a)). In these tests, the friction coefficient decreased gradually after the test started, i.e., a running-in to build the ULF state. During testing, several "spikes" appeared in the friction coefficient curve, representing an instantaneously increase and decrease of the detected friction coefficient. However, some of the tests did not achieve the ULF state (Fig. 3(b)). The friction coefficient cannot decrease to the ULF level, but keep in a relative high value.

The mean values of the final friction coefficients $(\bar{f})$ of each test were plotted in Fig. 4 . The tribosurfaces with higher roughness values performed better in these tests. Except at $120{ }^{\circ} \mathrm{C}$, the tests on the original sintered surfaces always achieved the ULF states with good repeatability. However, except at $40{ }^{\circ} \mathrm{C}$ or $120^{\circ} \mathrm{C}$, the ULF states were built only randomly on the mechanical polished surfaces.

In this context, most of the published researches were based on a uniform velocity, i.e., a rotary motion. This is the first time that a stable ULF state was achieved under a non-uniform velocity condition. The lowest detected friction coefficient was 0.004 . This result is lower than or consistent with the published values (on the basis of a uniform velocity): 0.005 from [20], 0.01 from $[3,8,9]$, and 0.02 from $[4,21]$.

The temperature influence is not directly clear yet. At $120{ }^{\circ} \mathrm{C}$, the liquid lubrication film could be easily
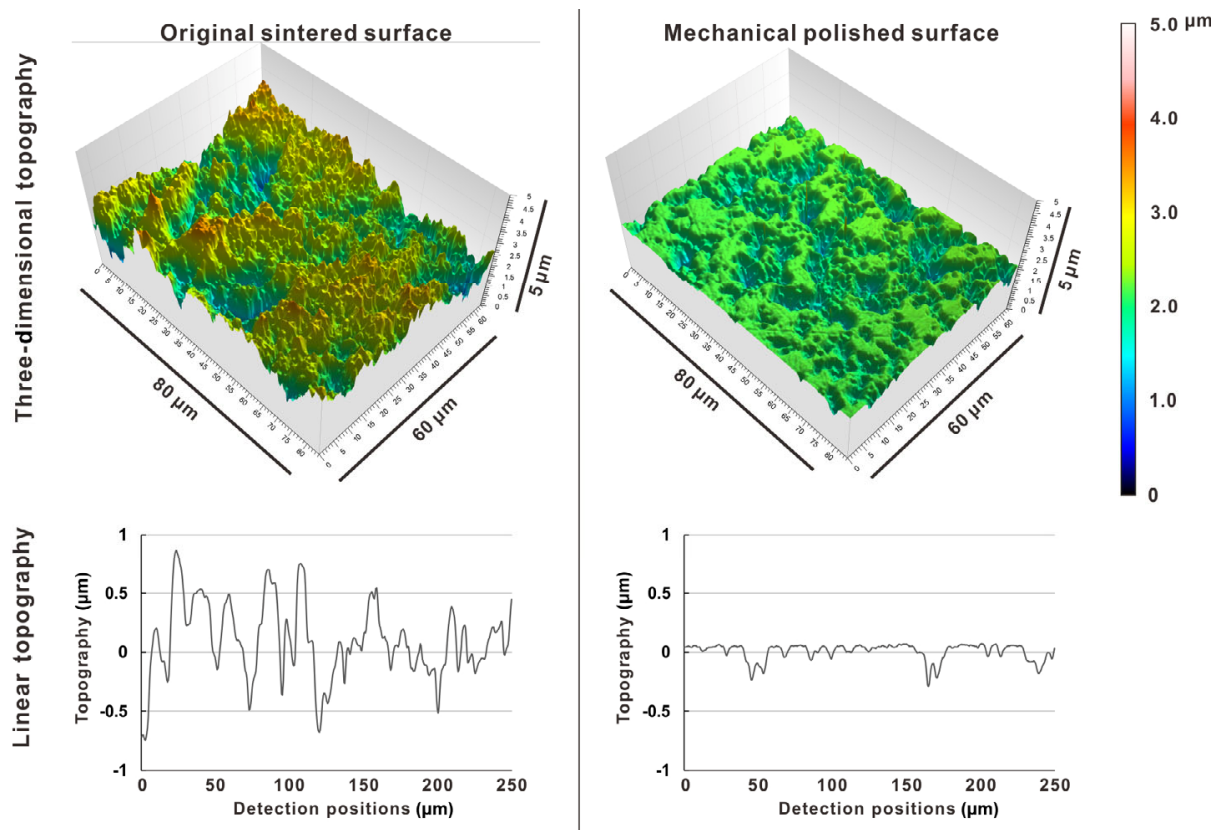

Fig. 2 Three-dimensional and linear topography of the tribo-surfaces before testing. 
(a) ultra-low friction test (original sintered surface, $80^{\circ} \mathrm{C}$ )

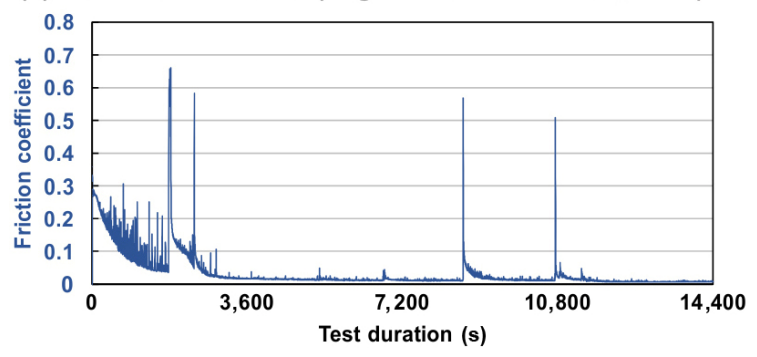

(b) non-ultra-low friction test (polished surface, $80^{\circ} \mathrm{C}$ )

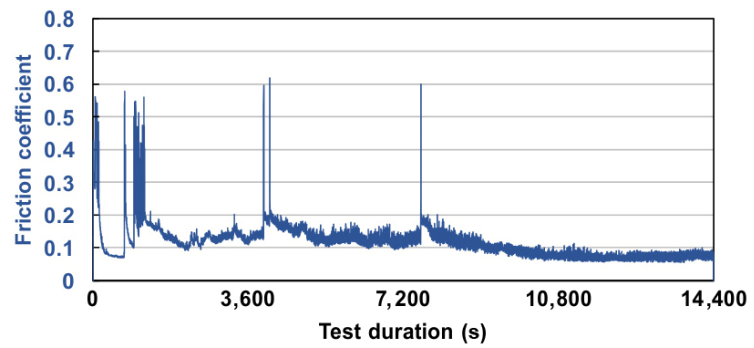

Fig. 3 In-situ friction coefficient records for two typical tests: (a) an ultra-low friction test ( $\bar{f}=0.009 \pm 0.0005$ ), the test ran at $80{ }^{\circ} \mathrm{C}$ between the original sintered rough surfaces; (b) a nonultra-low friction test $(\bar{f}=0.077 \pm 0.007)$, the test ran at $80{ }^{\circ} \mathrm{C}$ between the original sintered rough surfaces.

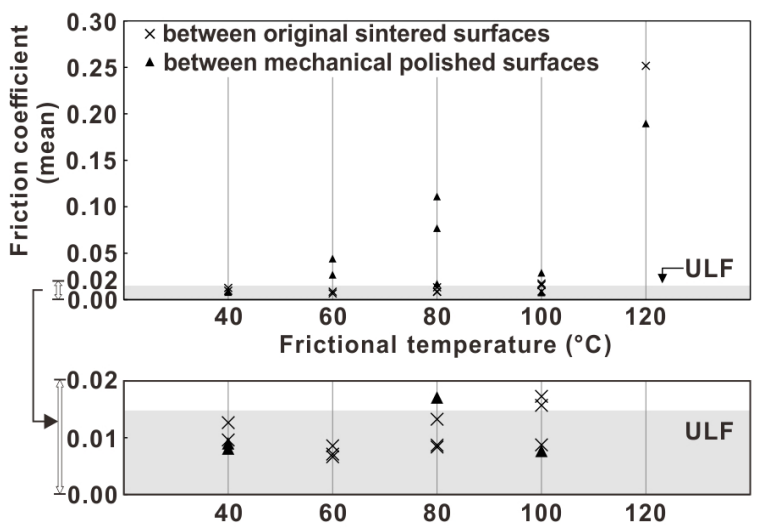

Fig. 4 Mean friction coefficients at different temperatures and surface roughness values.

vaporized and destroyed. However, in the lower temperature range, the temperature has minor influence on the ULF coefficient. This phenomenon is similar with the published findings [22-24]. The mechanism of the temperature influence is further discussed in the Section 3.3.

\subsection{Two wear features}

The wear scars from the upper and lower samples were locally different (Figs. 5(a) and 5(b)). From Fig. 5, two typical wear features were obtained: the abrasion-
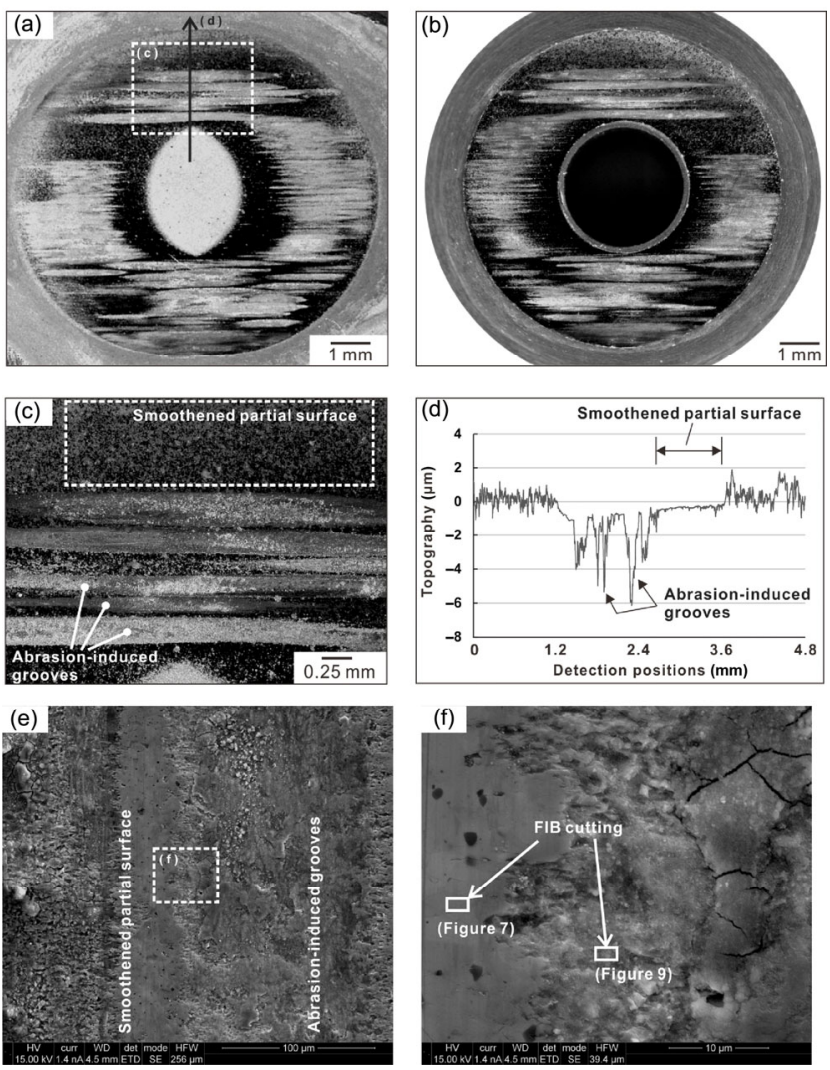

Fig. 5 Two typical wear features after the ULF test. $(a, b)$ the optical images of the lower and upper sample respectively from an ULF test $(\bar{f}=0.009 \pm 0.0005)$, the test ran at $60{ }^{\circ} \mathrm{C}$ between the original sintered surfaces; (c) the locally scaled image from (a); (d) the linear topography along the route in (a); (e) the SEM image of a regional wear surface including the both wear features; (f) the locally scaled image from (e) illustrating the FIB cutting positions for Figs. 7 and 9.

induced grooves and the smoothened partial surfaces. According to the linear topography in Fig. 5(d), the smoothened partial surface has a higher altitude than the abrasion-induced grooves.

This mixed wear condition is consistent with the observation from Presser et al. [25]. They conducted a scaled seal test on the flat tribo-surfaces without any surface texturing. This mixed wear condition from the surface-contact tests is different to that from the point-contact tests. In the point-contact tests which achieved the ULF state, such severe abrasion was not reported, while the only wear feature was the tribochemically smoothened surfaces $[2,9,10]$. These smoothened surfaces were the actual tribo-surfaces during the ULF state, and the tribo-gap was estimated less than $100 \mathrm{~nm}$ width. Thus, these smoothened surfaces and their closely mated condition were 
considered dominating the ULF state.

To check if the mating condition from the pointcontact tests is still applicable to the surface-contact cases, we evaluated the mating condition after both the non-ULF tests and ULF tests (Fig. 6). In the non-ULF cases, a meshing-microstructure was always found between the mated worn surfaces, shown by the ellipses in Fig. 6. A convex topographic feature indented into a concave one, generating a close contact condition. Considering the lubricant was pressed flowing from center to margin in the tribo-gap, i.e., from left to right in Fig. 6, these meshing-microstructures could cut off the liquid fluid, aggravating the lubrication effect. In contrast, such meshing-microstructure was never observed after the ULF tests. The corresponding abrasion-induced grooves had tolerance between them, as shown by white arrows in Fig. 6. A large distance (approx. $10 \mu \mathrm{m}$ ) existed between the surfaces of the mated concave features. This is much larger than the tribo-scale range. Therefore, the only contact part in the ULF cases was the mated smoothened partial surfaces. This mating condition is same with that from the reported point-contact tests.

\subsection{Smoothened partial surface}

To check if the smoothened surface from the surfacecontact tests is same with that from the reported point-contact tests, further surface analysis was conducted.

The surface roughness of the obtained smoothened partial surface was evaluated. The linear roughness of the obtained smoothened partial surface in Fig. 5(c) was $R a=10 \pm 4 \mathrm{~nm}, \mathrm{Rz}=150 \pm 51 \mathrm{~nm}$. This value is consistent with the published results from the pointcontact tests $[3,4,20]$. However, in the surface-contact tests, the obtained surface roughness locally differed in different smoothened surface regions. The minimal and maximum linear surface roughness Ra were $5 \mathrm{~nm}$ and $65 \mathrm{~nm}$, respectively.

The microstructure and elemental containment of the obtained smoothened partial surface were evaluated. The FIB cross-section beneath a plateau of the smoothened partial surface is shown in Fig. 7 (the FIB cutting position is illustrated in Fig. 5(f)). From the SEM image, the top surface was flattened. No debris adhered on the plateau surface. From EDX
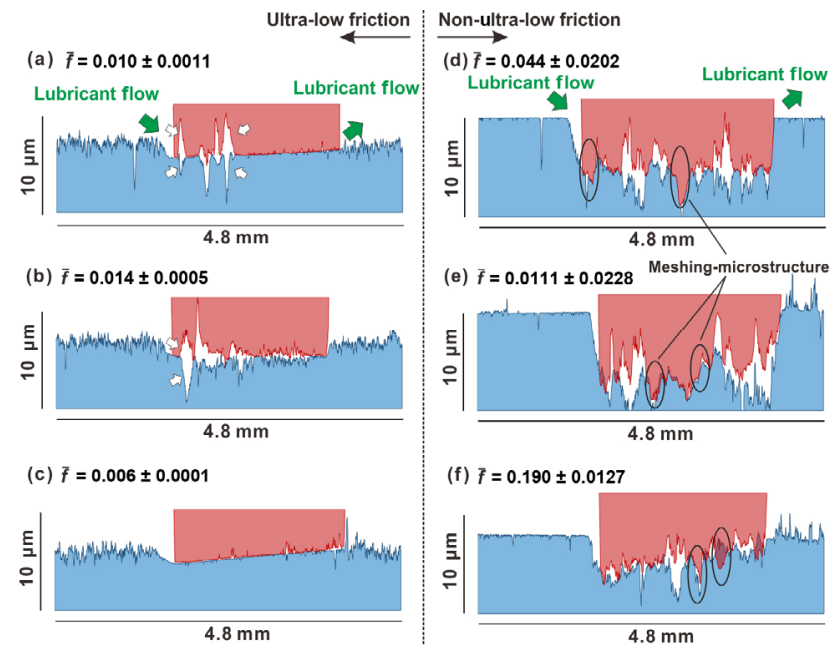

Fig. 6 Mating states after six tribo-tests. The final mean friction coefficients are marked in each measurement. The tests in (a), (b) and (c) achieved the ULF state, while the tests in (d), (e) and (f) did not achieve the ULF state. The testing parameters are ("surface R" represents the original sintered rough surfaces, "surface P" represents the mechanical polished surfaces): (a) surface $\mathrm{R}, 40{ }^{\circ} \mathrm{C}$; (b) surface $\mathrm{R}, 80^{\circ} \mathrm{C}$; (c) surface $\mathrm{R}, 60{ }^{\circ} \mathrm{C}$; (d) surface $\mathrm{P}$, $60{ }^{\circ} \mathrm{C}$; (e) surface $\mathrm{P}, 80^{\circ} \mathrm{C}$; (f) surface $\mathrm{P}, 120^{\circ} \mathrm{C}$.

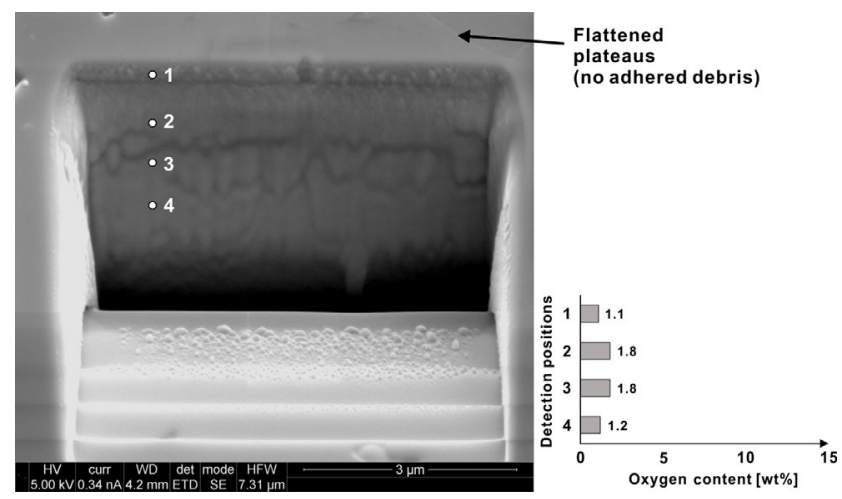

Fig. 7 SEM image and EDX analysis on the FIB cross-section beneath a plateau of smoothened partial surface. The FIB position is illustrated in Fig. 5(f).

analysis, little oxygen content was detected at the four points along the depth direction, only 1 to $2 \mathrm{wt} \%$. This little oxygen content might come from the accidental oxidation during FIB cutting. But this conclusion is only effective in a hundred-nanometer scale because of the limitation of EDX. Therefore, beneath the smoothened partial surface, an extensive oxidation deep into the bulk material did not proceed.

The microstructure and elemental containment of the smoothened partial surface have agreement with those from the published point-contact tests $[4,20]$. 
Its genesis mechanism is the tribo-chemical wear [2, $4,6,10]$, which is widely accepted. The local compression or micro-collision between $\mathrm{SiC}$ asperities generate locally concentrated stress (tens of gigapascal [26]) and high flash temperature (thousand centigrade $[27,28]$ ), activating the oxidation reaction (Eqs. (1) and (2)) $[3,23]$. Thus, the $\mathrm{SiC}$ is transformed to $\mathrm{SiO}_{2}$. No matter in which state the generated $\mathrm{SiO}_{2}$ exists, i.e., amorphous or crystalline [25], hydrated or not [6, 10], its hardness is at the most half of that of $\mathrm{SiC}$ [29]. If this oxidized layer endures a further solid-to-solid rubbing, it can be preferentially stripped from the bulk substrate material, as a sacrificial layer. The mating condition in Fig. 6 confirms a continuous rubbing process between these mated smoothened partial surfaces. Thus, the oxidized layer did not exist here. This is the reason for the absence of oxygen. This mechanism dominates the smoothening procedure for the SiC surface.

$$
\begin{gathered}
\mathrm{SiC}+2 \mathrm{H}_{2} \mathrm{O} \rightarrow \mathrm{SiO}_{2}+\mathrm{C}+2 \mathrm{H}_{2} \\
\mathrm{SiC}+4 \mathrm{H}_{2} \mathrm{O} \rightarrow \mathrm{SiO}_{2}+\mathrm{CO}_{2}+4 \mathrm{H}_{2}
\end{gathered}
$$

The testing temperatures had little influence on the frictional behaviors. This is because in the tribo-cases when the tribo-chemical reactions take place, the frictional behaviors would be dominated by the tribochemical reactions rather than the traditional lubricant film $[23,30]$. In the water lubricated SiC tribo-cases, the testing temperatures (for instance, $120^{\circ} \mathrm{C}$ or $300{ }^{\circ} \mathrm{C}$ from [3], or $40{ }^{\circ} \mathrm{C}$ to $120^{\circ} \mathrm{C}$ in this research) cannot represent the activation temperature for the tribochemical reactions. They were one order of magnitude lower than the instantaneous temperature between the contacting asperities (flash temperature). This flash temperature activated the oxidation reactions in Eq. (1) or (2). Therefore, the testing temperatures were too low to influence the tribo-chemical reactions, and the influence on the friction behavior was thus slight.

Compared to the reported point-contact tests, the observed smoothened partial surface from the surface-contact tests has the same roughness value, microstructure and oxidation condition. Additionally, the smoothened partial surface was verified as the only contact part during ULF state in the surface-contact tests. Therefore, we concluded that the tribo-chemical smoothening process in the point-contact tests functioned partially in the surface-contact tests. As reported, running-in in a point-contact test is a tribo-chemical smoothening process initiating from a contact point. In a surface-contact case, the same process happens between numerous surface asperities simultaneously. From this perspective, the tribo-chemical smoothening mechanism could theoretically work in a surface-contact case. The only difference exists on the additional severe abrasive wear.

\subsection{Abrasion-induced grooves}

In this study, severe abrasive wear occurred besides the tribo-chemically smoothened partial surfaces. This is not acceptable if the tribo-chemical smoothening procedure is used to manufacture mechanical seal faces. Thus, in this Section 3.4, the abrasion mechanism is analyzed and discussed to find the method to prevent the abrasive wear.

The abrasion-induced grooves were parallel and continuous. A typical groove is imaged in Fig. 8. Most of the grooves were longer than $1 \mathrm{~mm}$. Ring-like micro-cracks were observed around the both ends or shores of the groove, as shown by arrows in Fig. 8 . Most of the grooves presented a wedge shape on one of or the both ends. In these wedges, with the width decreased, the depth also decreased.

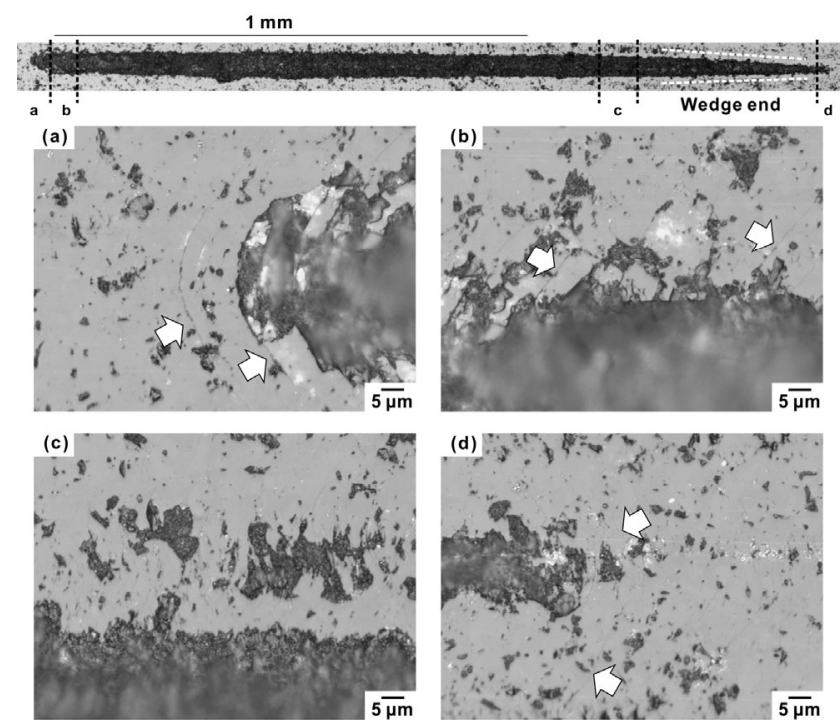

Fig. 8 A typical abrasion-induced groove and its locally scaled images. This groove was from the lower wear scar after an ULF test $(\bar{f}=0.008 \pm 0.0006)$. The test ran at $100{ }^{\circ} \mathrm{C}$ between mechanical polished surfaces. 
These abrasion-induced grooves were generated due to a ploughing procedure. The ring-like micro-cracks on the both ends of these grooves (the magnified images for both ends of a groove in Fig. 8) indicate the circumferential direction of a high tensile stress. This is a typical stress distribution feature around a point-contact center. Considering the low fracture toughness of $\mathrm{SiC}$, these micro-cracks were caused by a local point-contact with a high Hertz pressure [31]. After indentation, the indenting hard object was taken to conduct the linear sliding motion, thus the bulk material was ploughed.

Wear debris were involved into the ploughing procedure, as the third-body. This is because the grooves were mostly longer than $1 \mathrm{~mm}$, which is the stroke length of the frictional tests. This is a direct evidence to the involvement of third-body. In addition, the wedge end of this groove is also a typical feature of the third-body abrasion [32]. Therefore, as the only possible particle as the third-body, the wear debris joined and aggravated the wear condition.

The FIB-SEM-EDX analysis in Fig. 9 further proved this ploughing procedure. A porous layer was found beneath the worn surface (Fig. 9(b)). This layer had a loosely connected microstructure, implying a weak mechanical property. The EDX analysis indicated an oxygen-rich nature for this layer. Its thickness was approx. 1 to $2 \mu \mathrm{m}$. Its formation mechanism is attributed to the $\mathrm{SiC}$ oxidation. In this process, the high flash temperature provided the kinetic energy to activate the oxidation reactions (Eqs. (1) and (2)). This high flash temperature was generated due to the rupture of $\mathrm{SiC}$ substrate material, which was estimated higher than $1,000{ }^{\circ} \mathrm{C}[27,28]$. It should be noted that this oxygen-rich layer has the same chemical nature with the sacrificial layer during the tribo-chemical wear. The observed oxygen-rich feature and the loose microstructure support the proposed working mechanism of the sacrificial layer.

Numerous wear debris were observed from the locally magnified SEM image in Fig. 9(a). These debris adhered on the surface and they were not removed by the ultrasonic cleaning after the tests. Most of these debris had the diameter smaller than $1 \mu \mathrm{m}$ (Fig. 9(a)). These debris were the smashed debris from the stripped material during abrasion. The smashed debris were combined onto the substrate surface due
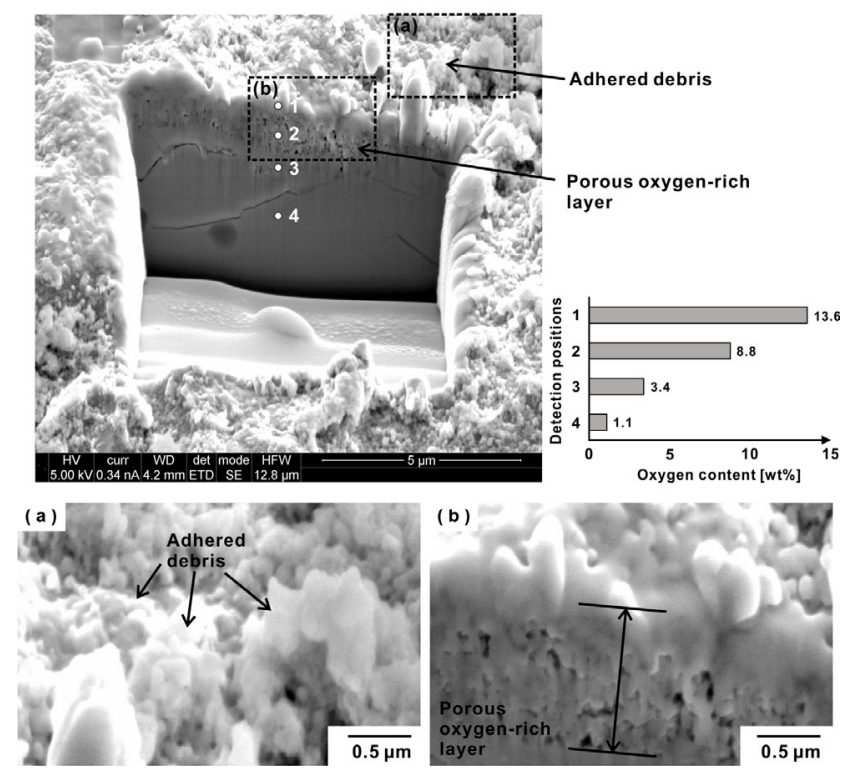

Fig. 9 SEM images and EDX analysis on the FIB cross-section beneath an abrasion-induced groove. The FIB position is illustrated in Fig. 5. $(a, b)$ Locally scaled from the main SEM image.

to a dehydration mechanism between the hydrated oxidation shells on the wrecked bulk material and wear debris [29, 33].

The ploughing initiated from a locally boundary lubrication. During ploughing, wear debris aggravated the wear condition as the third body. In the surfacecontact tribo-tests, the lubricant was possibly lacked locally. A locally boundary lubrication appeared, meanwhile a poor cooling condition occurred. The local deformations and micro-ruptures of the bulk material generated and accumulated energies, "heating" the local surface. Meanwhile, less oxidation occurred here due to the lack of water. Less sacrificial silica layer thus existed between the bare $\mathrm{SiC}$ surfaces. More mechanical micro-ruptures proceeded, causing a higher local temperature. This high temperature induced an inhomogeneous contact, as well as a high concentrated stress. Under this condition, a severe adhesion or abrasion could proceed, generating large particles and initiating the observed abrasion. Additionally, a regenerative feedback existed for the genesis of the abrasion-induced grooves. During the ploughing, large pieces of materials were stripped from the bulk, forming the large debris. This debris could be brought to the other unworn regions, initiating another third-body abrasive wear.

The meshing-microstructure was generated due to 
the shortage of water. During running-in, if the water feeding condition was abundant, the tribo-chemical wear was the dominant wear mechanism, generating smooth surfaces only. This is particularly true because no such meshing-microstructure was ever observed in a point-contact case, which had abundant water. Assuming a meshing-microstructure between the convex and concave features in aqueous environments, the convex feature endured a higher temperature than the concave one because of a weaker heat conduction situation. Thus, it had a higher oxidation rate. After oxidation, following the dissolution characteristic of silica, the generated silica on the convex feature dissolved at a higher rate than that on the concave one [29]. As a result, the convex topographic feature consumed faster than the concave one. With this mechanism proceeded, this meshing-microstructure would disappear. However, in the surface-contact test, water is possibly lacked in local regions, inducing a poor lubrication and a weak oxidation condition. The sacrificial silica layer cannot fully generate. The tribochemical smoothening mechanism lost its function and the meshing-microstructure cannot be consumed, causing a relative high friction coefficient.

The shortage of water is the main reason for the obtained higher friction coefficient between the polished surfaces in Fig. 4. The linear surface mating conditions before tests were measured (Fig. 10). The tolerance between the polished surfaces was at the most hundreds of nanometers. In contrast, a tolerance of several micrometers was possible between the original sintered surfaces. Between the polished surfaces, the limited tolerance resulted in a water shortage condition. In this case, the initial meshing-microstructure cannot be oxidized and consumed. Local dry friction could occur, generating high contact stress and more wear debris. The friction coefficient would not decrease until the water feeding condition being optimized. In addition, the narrow tolerance caused a limited storage space for wear debris. The debris could accumulate, aggravating the water distribution.

As a summary, the obtained abrasion-induced grooves were generated due to a ploughing process. The local shortage of water initiated the ploughing, meanwhile the involved wear debris aggravated the wear condition. Therefore, an entirely water-fulfilled tribo-gap is necessary to avoid the severe abrasion. Methods to
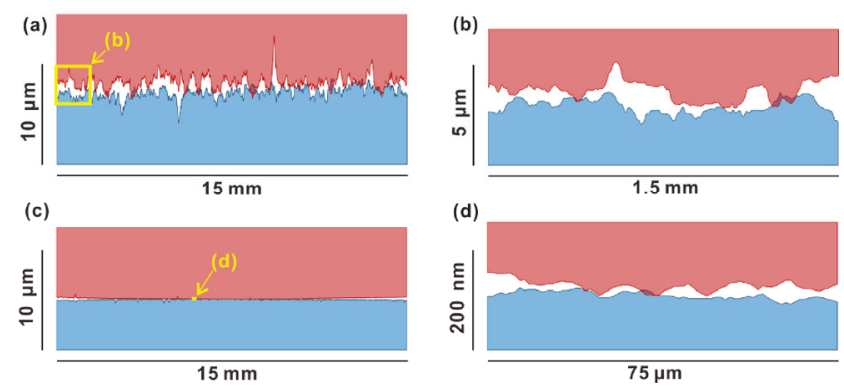

Fig. 10 Mated tolerance of the tribo-surfaces before testing. (a, b) are from the self-mated original sintered surfaces. (c, d) are from the self-mated mechanical polished surfaces.

decrease the size and amount of the wear debris are also meaningful.

\section{Conclusion and outlook}

In this study, the tribo-chemical smoothening process was researched by a series of surface-contact frictional tests. The lubrication condition was similar with the actual mechanical seals.

Compared to the reported point-contact tests, in the surface-contact cases, the tribo-surfaces were partially smoothened following the same tribo-chemical smoothening mechanism which proceeded between the numerous contacted asperities. After running-in, the same ultra-low friction state was built.

Besides the tribo-chemically smoothened partial surfaces, the severe abrasive wear occurred. The reason is attributed to the local shortage of water, which is a common condition in a surface-contact case similar with mechanical seals. The generated wear debris aggravated the wear condition as the third-body.

Therefore, it is theoretically possible to conduct the tribo-chemical smoothening process in the actual mechanical seals. The only problem in this process is the potential severe abrasive wear, which is mainly generated due to the shortage of water. In our further published paper, such abrasive wear can be avoided by introducing an additional buffer layer.

\section{Acknowledgement}

This research is supported by KSB AG, providing SiC samples. Authors are grateful to Dr. Stephan Bross, Mr. Frank Sehr, and Dr. Maike van Geldern from KSB AG for their constructive discussion on this 
work. The authors would also like to thank Dr. René Gustus from TU Clausthal for his help in the FIB measurements.

Open Access: The articles published in this journal are distributed under the terms of the Creative Commons Attribution 4.0 International License (http:// creativecommons.org/licenses/by/4.0/), which permits unrestricted use, distribution, and reproduction in any medium, provided you give appropriate credit to the original author(s) and the source, provide a link to the Creative Commons license, and indicate if changes were made.

\section{References}

[1] Dietzel W, Vasko J. The evolution and application of mechanical seal face materials. In 44th Turbomachinery \& 31st Pump Symposia, Houston, Texas, 2015: 1-16.

[2] Tomizawa H, Fischer T E. Friction and wear of silicon nitride and silicon carbide in water: Hydrodynamic lubrication at low sliding speed obtained by tribochemical wear. $A S L$ E Transactions 30(1): 41-46 (1987)

[3] Kitaoka S, Tsuji T, Katoh T, Yamaguchi Y, Kashiwagi K. Tribological characteristics of sic ceramics in high-temperature and high-pressure water. Journal of the American Ceramic Society 77(7): 1851-1856 (1994)

[4] Jordi L, Iliev C, Fischer T. Lubrication of silicon nitride and silicon carbide by water: running in, wear and operation of sliding bearings. Tribology Letters 17(3): 367-376 (2004)

[5] Chen M, Kato K, Adachi K. The difference in running-in period and friction coefficient between self-mated Si3N4 and $\mathrm{SiC}$ under water lubrication. Tribology Letters 11(1): 23-28 (2001)

[6] Xu J, Kato K. Formation of tribochemical layer of ceramics sliding in water and its role for low friction. Wear 245(1): 61-75 (2000)

[7] Zum Gahr K-H, Blattner R, Hwang D-H, Pöhlmann K. Micro- and macro-tribological properties of $\mathrm{SiC}$ ceramics in sliding contact. Wear 250(1): 299-310 (2001)

[8] Andersson P, Juhanko J, Nikkilä A-P, Lintula P. Influence of topography on the running-in of water-lubricated silicon carbide journal bearings. Wear 201(1): 1-9 (1996)

[9] Chen M, Kato K, Adachi K. Friction and wear of self-mated SiC and Si3N4 sliding in water. Wear 250(1): 246-255 (2001)

[10] Gates R, Hsu S. Tribochemistry between water and Si3N4 and SiC: Induction time analysis. Tribology Letters 17(3): 399-407 (2004)
[11] Kailer A, Amann T, Krummhauer O, Herrmann M, Sydow $\mathrm{U}$, Schneider M. Influence of electric potentials on the tribological behaviour of silicon carbide. Wear 271(9): 1922-1927 (2011)

[12] Wang X, Kato K, Adachi K. The lubrication effect of micro-pits on parallel sliding faces of $\mathrm{SiC}$ in water. Tribology Transactions 45(3): 294-301 (2002)

[13] Wong H-C, Umehara N, Kato K. Frictional characteristics of ceramics under water-lubricated conditions. Tribology Letters 5(4): 303-308 (1998)

[14] Guo F, Tian Y, Liu Y, Wang Y. Ultralow friction between cemented carbide and graphite in water using three-step ring-on-ring friction test. Wear 352-353: 54-64 (2016)

[15] Presser V, Krummhauer O, Nickel K G, Kailer A, Berthold C, Raisch C. Tribological and hydrothermal behaviour of silicon carbide under water lubrication. Wear 266(7): 771-781 (2009)

[16] Jin L, Scheerer H, Andersohn G, Oechsner M. Prüfkörperhalter und ein System zur Untersuchung eines Reibverhaltens. Application No. DE 102017118 902.5, 2017.

[17] Jin L, Scheerer H, Andersohn G, Oechsner M. Tribological behaviour of surface contact friction test with water lubricated at elevated temperatures. Tribologie und Schmierungstechnik 2017(3): 11-17 (2017)

[18] Patzer G, Ebrecht J. New approach to interpreting seizure tests on the translatory oscillation tribometer(SRV). In STLE Annual Meeting, Atlanta, 2017: Tribotesting 3J.

[19] Zhou W, Wang Z L. Scanning Microscopy for Nanotechnology. New York: Springer Science+Business Media, LLC, 2007.

[20] Matsuda M, Kato K, Hashimoto A. Friction and wear properties of silicon carbide in water from different sources. Tribology Letters 43(1): 33-41 (2011)

[21] Amutha Rani D, Yoshizawa Y, Hyuga H, Hirao K, Yamauchi Y. Tribological behavior of ceramic materials $\left(\mathrm{Si}_{3} \mathrm{~N}_{4}, \mathrm{SiC}\right.$ and $\mathrm{Al}_{2} \mathrm{O}_{3}$ ) in aqueous medium. Journal of the European Ceramic Society 24(10-11): 3279-3284 (2004)

[22] Kitaoka S, Tsuji T, Katoh T, Yamaguchi Y, Sato K. Tribological characteristics of $\mathrm{Si} 3 \mathrm{~N} 4$ ceramic in hightemperature and high-pressure water. Journal of the American Ceramic Society 77: 580-588 (1994)

[23] Kitaoka S, Tsuji T, Yamaguchi Y, Kashiwagi K. Tribochemical wear theory of non-oxide ceramics in high temperature and high-pressure water. Wear 205(1-2): 40-46 (1997)

[24] Muratov V A, Luangvaranunt T, Fischer T E. The tribochemistry of silicon nitride: Effects of friction, temperature and sliding velocity. Tribology International 31(10): 601-611 (1998) 
[25] Presser V, Nickel K G, Krummhauer O, Kailer A. A model for wet silicon carbide tribo-corrosion. Wear 267(1): 168-176 (2009)

[26] Presser V. Oxidation and wet wear of silicon carbide. Tübingen, 2009.

[27] Kuhlmann-Wilsdorf D. Flash temperatures due to friction and Joule heat at asperity contacts. Wear 105(3): 187-198 (1985)

[28] Quinn T F J. Computational methods applied to oxidational wear. Wear 199(2): 169-180 (1996)

[29] Iler R K. The Chemistry of Silica: Solubility, Polymerization, Colloid and Surface Properties, and Biochemistry. New

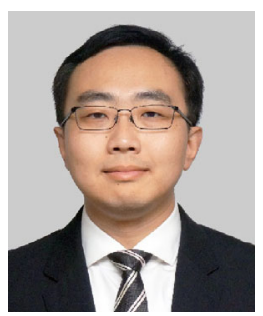

Le JIN. He received his bachelor and master degrees in 2007 and 2009, respectively, both from the Department of Mechanical Engineering, Tsinghua University, China. In 2018, he obtained the PhD. degree

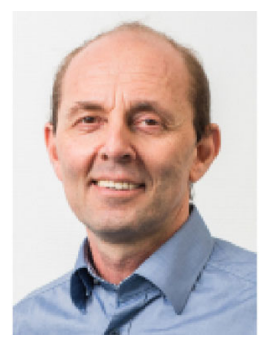

Herbert SCHEERER. He received his diploma and doctorate in physics from the University of Heidelberg, Germany, in 1992 and 1998, respectively. Since 1999 he has been
York, Chichester: Wiley, 1979.

[30] Hsu S M., Zhang J, Yin Z. The nature and origin of tribochemistry. Tribology Letters 13(2): 131-139 (2002)

[31] Lawn B R. Indentation of ceramics with spheres: A century after Hertz. Journal of the American Ceramic Society 81(8): 1977-1994 (1998)

[32] Denape J. Third body concept and wear particle behavior in dry friction sliding conditions. KEM 640: 1-12 (2015)

[33] Zhuravlev L T. The surface chemistry of amorphous silica. Zhuravlev model. Colloids and Surfaces A: Physicochemical and Engineering Aspects 173(1): 1-38 (2000)

in tribology from Techniche Universität Darmstadt, Germany. His current position is an R\&D senior manager in Shanghai Electric-KSB Nuclear Pumps \& Valves Co., Ltd. His research interests include superlubricity, tribology in bearings \& seals of pumps, water lubrication and tribo-chemistry.

working at the Center for Structural Materials, Technische Universität Darmstadt, Germany. He is responsible for tribology and functional surfaces in the field of surface technology. 